Baseline

\title{
PCDD/Fs in sediments of Central Vietnam coastal lagoons: In search of TCDD
}

\author{
Rossano Piazza ${ }^{\mathrm{a}, \mathrm{b}}$, Silvia Giuliani ${ }^{\mathrm{c}, *}$, Luca Giorgio Bellucci ${ }^{\mathrm{c}}, \mathrm{Cristian}_{\text {Mugnai }}{ }^{\mathrm{c}}$, Nguyen Huu Cu$^{\mathrm{d}}$, \\ Dang Hoai Nhon ${ }^{d}$, Marco Vecchiato ${ }^{a}$, Stefania Romano ${ }^{c}$, Mauro Frignani ${ }^{c}$ \\ a University Ca' Foscari, Dorsoduro 2137, 30123 Venice, Italy \\ ${ }^{\text {b } C N R-I s t i t u t o ~ p e r ~ l a ~ D i n a m i c a ~ d e i ~ P r o c e s s i ~ A m b i e n t a l i, ~ D o r s o d u r o ~ 2137, ~} 30123$ Venezia, Italy \\ ${ }^{\mathrm{c}}$ CNR-Istituto di Scienze Marine, Via Gobetti 101, 40129 Bologna, Italy \\ ${ }^{\mathrm{d}}$ Institute for Marine Environment and Resources, 246 Da Nang Street, Haiphong City, Viet Nam
}

\section{A R T I C L E I N F O}

\section{Keywords:}

Dioxins

Furans

Sediments

Soils

Reservoirs

Central Vietnam

\begin{abstract}
A B S T R A C T
Samples from nine Central Vietnam coastal lagoons, together with three soils and sediments collected in two freshwater reservoirs of the Thua Thien-Hué province, were analysed for polychlorinated dibenzo-pdioxins and dibenzofurans (PCDD/Fs). Total concentrations are low, from 192 to $2912 \mathrm{pg} \mathrm{g}^{-1}$ and depth profiles in Tam Giang-Cau Hai (TG-CH) sediment cores show only minor changes over time in PCDD/F input and composition. Octachloro dibenzo-p-dioxin (OCDD) is the prevailing congener (approximately $90 \%$ ), indicating combustion as the main PCDD/F source to these coastal systems, whereas natural formation might be partly responsible for the presence at depth. 2,3,7,8-Tetrachloro dibenzo-p-dioxin (TCDD), largely sprayed together with Agent Orange over the study areas during the war (1961-1971), is absent or very low. This result supports the hypothesis of strong degradation soon after spraying. Multivariate statistical analyses account for the presence of local, short-range sources as observed in the northern part of the TG-CH lagoon.
\end{abstract}

(c) 2010 Elsevier Ltd. All rights reserved.
2,3,7,8-Tetrachloro dibenzo-p-dioxin (TCDD) was extensively sprayed over most of the Vietnamese territory south of the 17th parallel, in 1961-1971 during the 2nd Indochinese war, as a contaminant of Agent Orange, a herbicide used to deprive opposing forces of strategic cover and food (Dwernychuk et al. 2002; Stellman et al. 2003; Young et al., 2004). The TCDD load resulting from aerial spray applications over the forests is thought to have disappeared a few hours after the spraying, thanks to photodegradation processes taking place in the wax layer over the leaf cuticle, as reported by Young et al. (2004) and references therein. However, according to Dwernychuk et al. (2002) and Mai et al. (2007), very high TCDD concentrations were still measured in the late 1990s in the so-called "hot spots", generally soils in and around former US military installations where Agent Orange was stored (e.g., the A Luoi Valley and the city of Da Nang in Central Vietnam, and the city of Bien Hoa in southern Vietnam). Moreover, elevated TCDD levels were measured also in the components of the human food chain (i.e. environmental matrices and living organisms that form the food chain where humans are the ultimate consumers; Dwernychuk et al., 2002), food and wildlife (Olie et al., 1989), as well as in people from the most contaminated areas (Schecter

* Corresponding author. Address: Consiglio Nazionale delle Ricerche Istituto di Scienze Marine, Sede di Bologna, Via Gobetti, 101, 40129 Bologna, Italy. Tel.: +39 051 6398864; fax: +390516398940.

E-mail address: silvia.giuliani@bo.ismar.cnr.it (S. Giuliani). et al., 2001, 2002, 2003; Dwernychuk et al., 2002), in accordance with the general population's route of exposure that proceeds almost exclusively through consumption of animal foods, including meat, fish, and dairy products (Startin and Rose, 2003; EPA, 2004).

In spite of such large amount of information, very little is known about the contamination of other areas in Vietnam, especially the central provinces, that are presently experiencing a great economic development and where the large Tam Giang-Cau Hai lagoon and other minor coastal lagoons are located. Also these provinces were affected by military operations during the war (Stellman et al., 2003) and local authorities of the Thua ThienHué province report that as many as 6633 families have been affected by diseases (chronic conditions, skin disorders, asthma, cancers and gastrointestinal disease) linked to the Agent Orangedioxin (the poisoning is evidently still acting since 3708 sick people are under 16; Scott-Clark and Levy, 2003), but nothing is known about the PCDD/F environmental contamination of the territory. The analysis of sediment records can partially fill this gap, as they provide information on environment quality, contaminant sources, history and trends of pollutant delivery (e.g., Goff, 1997; Yamashita et al., 2000; Frignani et al., 2001; Moon et al., 2009). Therefore, the aim of this work is to assess PCDD/F contents, with a particular emphasis on TCDD, in sediments of Central Vietnam coastal lagoons, and in selected soils and reservoirs of the Thua Thien-Hué province, as indicator of watershed contamination levels. 


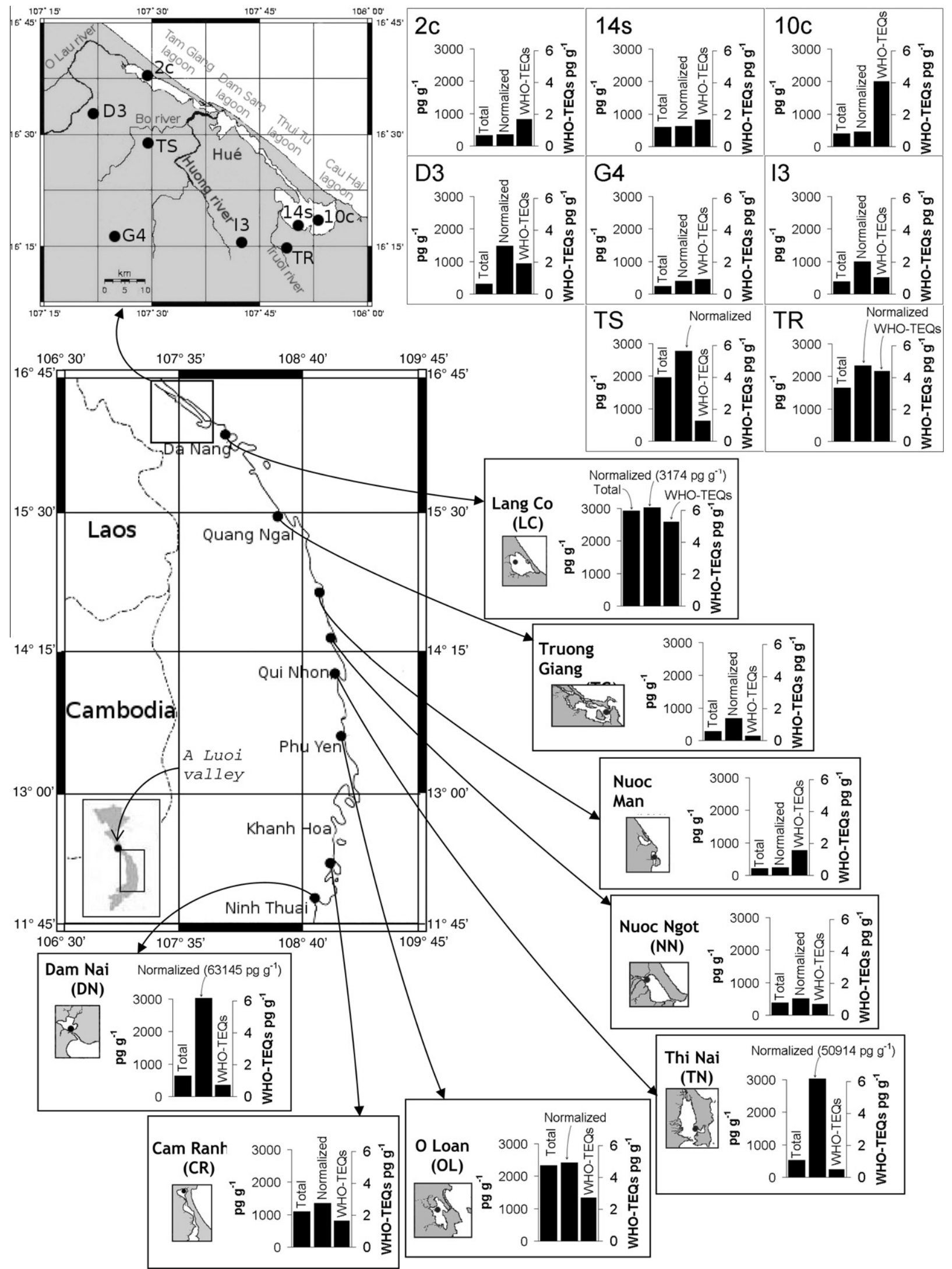

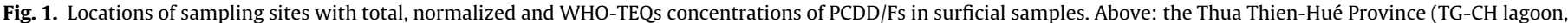
TR and TS reservoirs, and soils D3, G4, I3). Below: Central Vietnam lagoons.

The nine Central Vietnam coastal lagoons taken into consideration (Fig. 1) have surface areas ranging from 2.8 to $216 \mathrm{~km}^{2}$ and can be classified (Cu, 1995) as very small (Dam Nai, DN), small (Lang Co, LC; Nuoc Man, NM; Nuoc Ngot, NN and O Loan, OL), 
medium (Truong Giang, TG and Thuy Trieu, connected to Cam Ranh Bay, CR), and large (Thi Nai, TN; Tam Giang-Cau Hai, TG-CH). The environmental quality of these lagoons has been deeply affected over time by anthropogenic pollution, as shown by high concentrations of oil, nitrate and coliform bacteria in water (Dieu, 2006; Thom, 2006), mainly related to the surrounding highly populated areas. In addition, Frignani et al. (2007) discussed polychlorinated biphenyl (PCB) concentrations in sediment cores of the TG-CH lagoon and their data showed no significant improvement in recent times. On the other hand, PCB surficial values were not high compared with polluted environments worldwide. The same low contamination levels were observed by Giuliani et al. (2008) when discussing the patterns of polycyclic aromatic hydrocarbons (PAHs) in sediment cores from the nine lagoons. However, also PAHs present in some cases (i.e. the TG-CH, LC, TG and TN lagoons) higher concentrations in surficial levels that account for increased anthropogenic pressures in recent times that need to be carefully monitored.

Study areas and sampling locations are shown in Fig. 1. Two sediment cores (02c and 10c) were collected from TG-CH in December 2002 together with a surficial sample (14s). The three soils (D3, G4 and I3) and the sediment from LC were obtained in June 2004, whereas the other seven lagoons were sampled in June 2005. Soils were taken from locations far from cultivated fields or any other working activity, providing that their formation remained undisturbed over the years. Finally, sediments from two small reservoirs in the Thua Thien-Hué province, TR and TS, were collected in July 2006.

A manual piston corer was used to retrieve both surficial samples and short cores from lagoons, whereas a Van Veen grab was used for the reservoirs. After collection, the cores were extruded and sectioned at intervals of $2-4 \mathrm{~cm}$, with higher resolution at the top. Short soil cores ( $\max 5 \mathrm{~cm}$ ) were collected by inserting a Plexiglas tube into the ground and then subdivided into $2-2.5 \mathrm{~cm}$ thick samples. Sediment and soil slabs were then put in polyethylene vessels and stored at $0{ }^{\circ} \mathrm{C}$. Once in the laboratory they were kept at $-18^{\circ} \mathrm{C}$ until freeze-drying and disaggregation.

Grain size analyses were carried out by wet sieving, to separate sands, after a pre-treatment with $\mathrm{H}_{2} \mathrm{O}_{2}$. Silt and clay fractions were determined with a X-ray Micrometric SediGraph. The results have been already published by Frignani et al. (2007) and Giuliani et al. (2008) and are here reported for completeness.

The analysis of PCDD/Fs was implemented starting from the USEPA 1613 method for the determination of 17 priority congeners. PCDD/Fs were analysed in all sediment and soil surficial samples (Table 1). In addition, concentration-depth profiles were obtained for cores $02 \mathrm{c}$ and $10 \mathrm{c}$ from TG-CH (Fig. 1). Freeze-dried samples were extracted three times with toluene, at temperature of $130^{\circ} \mathrm{C}$ and pressure of 130 bar in a PSE One ${ }^{\circledR}$ (Applied Separation Inc., Allentown, PA, USA) system, in presence of anhydrous $\mathrm{Na}_{2} \mathrm{SO}_{4}$ and activate copper, after the addition of a EDF 8999 solution (Cambridge Isotope Laboratories) containing $15{ }^{13} \mathrm{C}$-labeled $\mathrm{PCDD} / \mathrm{F}$ congeners as internal standards. The clean-up was performed using the automatic system Power Prep ${ }^{\circledR}$ (Fluid Management System Inc., Waltam, MA, USA) after transfer of the extracts to hexane. Samples were eluted with solvents through two prepacked disposable columns containing multilayer silica and alumina, respectively. The high resolution gas chromatography-mass spectrometry (HRGC/HRMS) analyses were carried out using a gas chromatograph Agilent G6890 Series GC System coupled to a FINNIGAN MAT 95XP mass spectrometer operating in EI mode at $45 \mathrm{eV}$ and source temperature of $260^{\circ} \mathrm{C}$. Resolution was 10,000 , using MID (Multiple Ion Detection) in Lock Mode. Accuracy was checked through the analysis of a certified standard (DX1; National Water Research Institute, USA), repeated for every batch, verifying that the results were within the uncertainty interval. Precision was better than $1 \%$ on the total, and $1-39 \%$ for the single congeners, with the highest uncertainties associated to the lowest values. Both extraction and purification blanks were checked for every sample. Concentrations were corrected for recoveries (estimated with the mixture EDF 5999, Cambridge Isotope Laboratories) that ranged between $87 \%$ and $95 \%$.

Table 1 shows the grain size composition of surficial samples. The percent content of fine particles (silt plus clay) is $70-90 \%$ except in soils (20-59\%) and at TN and DN where sediments were almost entirely sandy. Surficial samples from sites $02 \mathrm{c}$ and $10 \mathrm{c}$ in the TG-CH lagoon are fine but both cores, though from very different part of the system, show major changes at depth (approximately $30 \mathrm{~cm}$ depth for core $02 \mathrm{c}, 17$ and $10 \mathrm{~cm}$ depth for core $10 \mathrm{c}$ ) that were ascribed to the onset of higher hydrodynamic processes, with the removal of fine sediments. In the last years the water dynamics decreased again, leading to the higher accumulation of fine sediments close to the sediment-water interface (Frignani et al., 2007).

Frignani et al. (2007) calculated apparent sediment accumulation rates (SARs) of 0.31 and $0.60 \mathrm{~cm} \mathrm{y}^{-1}$ for cores $10 \mathrm{c}$ and $02 \mathrm{c}$, respectively. The authors suggested that occasionally the environment can get very dynamic (e.g., during typhoons), with a consequent loss of bottom sediments. This seems to be confirmed by the comparison of concentration-depth profiles of metals in cores sampled in 2002 and 2004 at sites 02c and 10c (unpublished results). The eight cores from minor lagoons provided apparent SARs ranging from 0.10 to $0.30 \mathrm{~cm} \mathrm{y}^{-1}$ (Giuliani et al., 2008).

Table 1

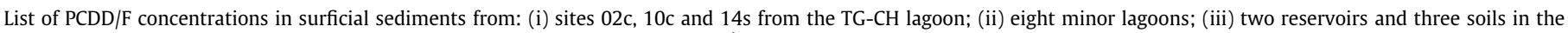

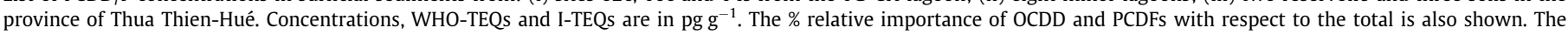
percent content of fines (silt plus clay) is listed, together with total PCDD/F values normalised to this sediment feature.

\begin{tabular}{|c|c|c|c|c|c|c|c|c|c|c|c|c|c|c|c|c|}
\hline & \multicolumn{11}{|l|}{ Lagoons } & \multicolumn{2}{|c|}{ Reservoirs } & \multicolumn{3}{|l|}{ Soils } \\
\hline & TG-CH 02c & TG-CH 10c & TG-CH $14 \mathrm{~s}$ & LC & TG & NM & NN & $\mathrm{TN}$ & OL & CR & $\mathrm{DN}$ & TR & TS & D3 & G4 & I3 \\
\hline Total & 310 & 391 & 581 & 2919 & 271 & 197 & 375 & 509 & 2314 & 1084 & 631 & 1633 & 1946 & 294 & 223 & 375 \\
\hline TCDD & 0.18 & 0.11 & 0.59 & 0.51 & n.d. & n.d. & n.d. & n.d. & n.d. & n.d. & n.d. & 0.37 & n.d. & 0.26 & n.d. & 0.68 \\
\hline I-TEQs ${ }^{\mathrm{b}}$ & 1.62 & 3.93 & 1.96 & 7.12 & 0.476 & 1.45 & 0.973 & 0.919 & 4.39 & 2.65 & 1.26 & 5.26 & 2.97 & 1.77 & 1.01 & 1.35 \\
\hline WHO-TEQs ${ }^{c}$ & 1.63 & 3.91 & 1.71 & 5.24 & 0.249 & 1.52 & 0.652 & 0.463 & 2.68 & 1.62 & 0.708 & 4.35 & 1.56 & 1.79 & 0.862 & 1.10 \\
\hline OCDD (\%) ${ }^{\mathrm{a}}$ & 91.1 & 85.8 & 90.4 & 95.1 & 92.8 & 83.7 & 93.5 & 95.2 & 95.7 & 94.4 & 95.0 & 95.9 & 97.6 & 94.1 & 94.8 & 97.4 \\
\hline PCDFs (\%) & 2.37 & 5.33 & 1.38 & 0.437 & 1.67 & 3.88 & 1.34 & 0.369 & 0.262 & 0.370 & 0.749 & 2.49 & 0.493 & 2.25 & 3.07 & 0.710 \\
\hline Fines $(\%)^{d}$ & 92 & 88 & 95 & 92 & 40 & 85 & 76 & 1.00 & 96 & 81 & 1.00 & 70 & 70 & 20 & 59 & 38 \\
\hline Normalised $^{\mathrm{e}}$ & 337 & 444 & 611 & 3173 & 678 & 232 & 494 & 50914 & 2411 & 1338 & 63145 & 2318 & 2765 & 1471 & 379 & 988 \\
\hline
\end{tabular}

n.d.: not detected.

a Calculated with respect to total PCDD/F concentrations.

b I-TEQs are calculated from TEFs proposed by NATO/CCMS, 1988.

c WHO-TEQs are calculated from TEFs proposed by Van den Berg et al., 2006.

d Silt plus clay (the values for TN and DN are assumed to be 1.00 but actually the sediment is entirely sandy).

e Total PCDD/F concentrations normalised to fine sediment fractions. 
Surficial PCDD/F concentrations range between 197 and $2919 \mathrm{pg} \mathrm{g}^{-1}$ (Table 1 ). The average surficial values measured in Vietnamese lagoons, reservoirs and soils are lower than most of those reported for other places worldwide, even when only OCDD concentrations can be compared. In Fig. 2, the reference data are grouped into: (i) contaminated areas (e.g., Miyata et al., 1995; Pieper et al., 1997; Rappe et al., 1997; Bellucci et al., 2000); (ii) coastal areas (e.g., Tyler and Millward, 1996; Dannenberg et al., 1997; Fattore et al., 1997; Koistinen et al., 1997; Wade et al., 1997; Müller et al., 1999, 2002; Bellucci et al., 2000; Sakurai et al., 2000; Gaus et al., 2001; Sericano et al., 2001; Dalla Valle et al., 2003; Naito et al., 2003; Koh et al., 2004; Okumura et al., 2004; Eljarrat et al., 2005; Hu et al., 2005; Danis et al., 2006; Suarez et al., 2006); and (iii) internal waters (e.g., Gifford et al. 1996; Rose and McKay, 1996; Schramm et al., 1997; Vartiainen et al., 1997; Isosaari et al., 2002; Ryoo et al., 2005). This accounts for generally low inputs, even if it seemed reasonable to expect higher concentrations of TCDD from the use of Agent Orange. When compared among themselves, lagoons show relatively higher PCDD/F surficial concentrations at LC, OL and CR, whereas the others are even one order of magnitude lower (e.g., TG and NM, Fig. 1 and Table 1). In turn, the values obtained for reservoir sediments (TR and TS, Fig. 1 and
Table 1) are comparable to those of the most contaminated lagoons. Furthermore, PCDD/F concentrations in reservoir sediments are higher than in nearby soils and this may call for a supplementary source, such as watershed drainage, coupled with the negligible photodecomposition in aqueous environments (Verschueren, 1983). Also concentrations in TG-CH lagoon surficial samples are slightly higher than in corresponding soils (Fig 1 and Table 1).

The large differences in grain size compositions among sites can have a significant effect on PCDD/F concentrations since it is generally assumed that contaminants are preferentially adsorbed onto the surface of fine particles, thus being lower in sandy sediments and soils. A normalisation to the content of silt plus clay can help getting rid of the grain size effect. Fig. 1 and Table 1 show that, theoretically, the most contaminated fine sediment would be that from TN and DN (50,914 and 63,145 $\mathrm{pg} \mathrm{g}^{-1}$, assuming a $1 \%$ content of fines), followed by LC, TS, OL, TR, D3 and CR (1338-3173 $\mathrm{pg} \mathrm{g}^{-1}$ ) with the others between 232 (NM) and 988 (I3) $\mathrm{pg} \mathrm{g}^{-1}$. According to these results, the PCDD/F input to the TN and DN lagoons should have been particularly high, because of the low retaining capacity of the very coarse bottom sediments. When normalised, concentrations in soils D3 and I3 become higher than those in lagoon samples but remain lower than PCDD/Fs in reservoir sediments.

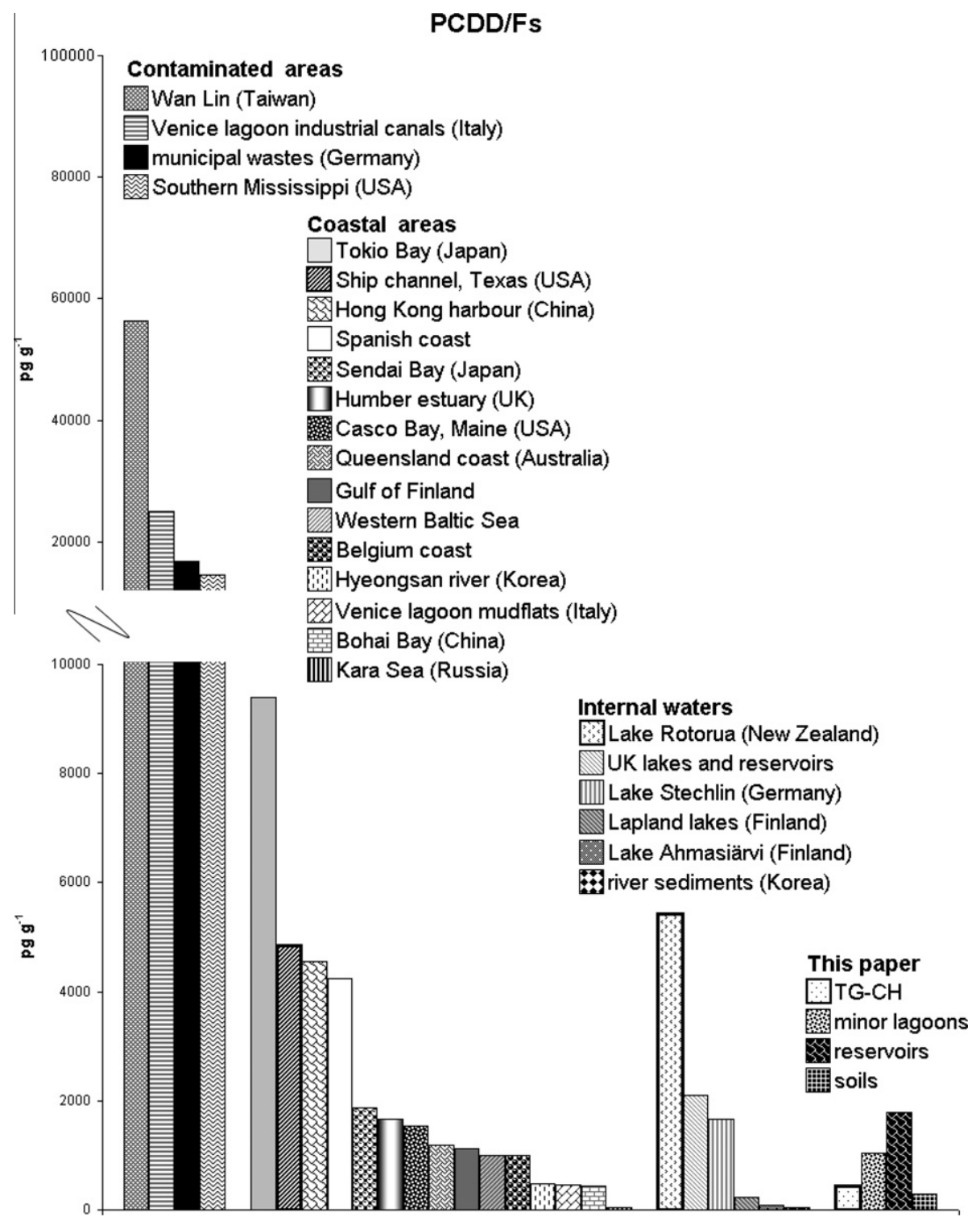

Fig. 2. Comparison between values of PCDD/Fs at the study sites (far right) and those reported in the literature for other locations worldwide. 
When calculated as I-TEQs (International Toxic Equivalents; NATO/CCMS, 1988), surficial values of our samples range from

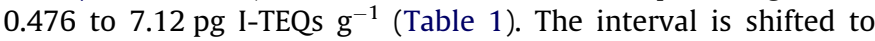
slightly lower values (0.249-5.24 pg WHO-TEQs $\mathrm{g}^{-1}$ ) if we consider the new toxic equivalents suggested by the World Health Organization in 2005 (Van den Berg et al., 2006). Maximum WHO-TEQs were observed at LC, TR and 10c (Fig. 1 and Table 1). These sites are located between the cities of Hue and Da Nang, thus indicating the predominance of local urban and industrial sources with respect to a widespread distributed contamination. Nevertheless, PCDD/F I-TEQs in our samples can be considered rather low, when compared, for example, to the acceptable limit set by the Italian legislation (Legislative Decree 152/06) for urban and civil soils (10 pg I-TEQs $\mathrm{g}^{-1}$ ). Based on these results, PCDD/Fs in soils and sediments of the Thua Thien-Hué province and in sediments of the southern minor lagoons do not represent a threat to the environment and the population, and the likely mobilisation from nearby hot spots (i.e. A Luoi in the Thua Thien-Hué province and the city of Da Nang) seems not to influence the lagoon system. These are important and good news for people living close to these water bodies. However, the problem of PCDD/F contamination remains relevant for those places, such as the A Luoi valley, that formerly hosted several US bases but are now occupied by villages, where civilians live and extensively rework the contaminated soils for agricultural purposes, as testified by a considerable amount of literature (Olie et al., 1989; Schecter et al., 2001, 2002, 2003; Dwernychuk et al., 2002; Scott-Clark and Levy, 2003; Stellman et al., 2003; Young et al., 2004; Mai et al., 2007). This is likely affecting TCDD levels in food from this region and the eastern watershed that feeds the Mekong River, but not the southeastern coastal locations object of the present study. Also the high TCDD values measured near Da Nang (Mai et al., 2007) are not paralleled by equally high values in the nearby LC lagoon. Here, particular geographical features (i.e. the lagoon is surrounded by mountains) act as physical barriers to the exchange with highly polluted areas.

Total PCDD/Fs in the two cores from TG-CH range between 192 and $478 \mathrm{pg} \mathrm{g}^{-1}$, with maxima at $12-14$ and $18-20 \mathrm{~cm}$ depth at site 02c and 10c, respectively (Fig. 3). In turn, WHO-TEQs (0.835$10.8 \mathrm{pg} \mathrm{g}^{-1}$ ) display a different pattern, especially in sediments from $10 \mathrm{c}$. Also these historical concentrations are largely below the above mentioned limit of 10 pg I-TEQs $\mathrm{g}^{-1}$, except at the time corresponding to $47-50 \mathrm{~cm}$ depth of core $10 \mathrm{c}$. At this level, the

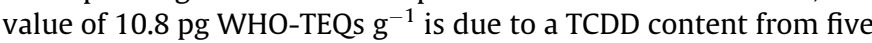
to ten times higher than in the overlying sediment sequence
(2.74 $\mathrm{pg} \mathrm{g}^{-1}$, corresponding to a contribution of $0.8 \%$ to the total PCDD/F concentration at this level, Fig. 3) but also furans and penta- to hexa-dioxins are relatively high. This particular situation could be the record of a period of intense Agent Orange spraying. For what we know (Frignani et al., 2007), the apparent date relative to this depth is well before the war period. It is worth noting, however, that the dynamic processes in the lagoon cause a high dating uncertainty (Frignani et al., 2007). In core 02c, the maximum WHO-TEQ (2.29 $\mathrm{pg} \mathrm{g}^{-1}$ ) at $19 \mathrm{~cm}$ depth corresponds to the minimum PCDD/F concentration (192 $\mathrm{pg} \mathrm{g}^{-1}$ ) due to the higher relative importance of HxCDDs and furans (above all PeCDFs) at this level (Fig. 3). The sand content in core 10 c (up to $17 \%$; Frignani et al., 2007) may account for the PCDD/F minimum at $12 \mathrm{~cm}$ depth, whereas the grain size composition seems less effective at 02c.

Homologue profiles are the basis for the source identification of PCDD/Fs in environmental samples (Hagenmaier et al., 1994; Bellucci et al., 2000; Moon et al., 2009, and references therein). Unfortunately, the 17 priority PCDD/Fs congeners do not include those indicative of specific production use (e.g., Moon et al., 2009) but some information can still be obtained. Table 1 and Figs. 3 and 4 show that OCDD is by far the dominant congener (80.597.6\% of total PCDD/Fs) in all samples, followed by $1,2,3,4,6,7,8$ heptachlorodibenzo-p-dioxin (HpCDD) that accounts only for $1.2-10.2 \%$. OCDD is produced by both natural and anthropogenic combustion processes (Fattore et al., 1997; Bellucci et al., 2000) that are widespread in the territory (transportations, heating, cooking, incineration, industry, etc.). Relatively high levels of OCDD were detected also by other authors in areas close to the Thua Thien-Hué province (Dwernychuk et al., 2002; Mai et al., 2007), probably reflecting the common habit of waste burning. PCDFs, that usually account for industrial pollution (Stringer et al. 1995; Fattore et al., 1997; Isosaari et al., 2000; Frignani et al., 2001), are almost absent or contribute very little to total concentrations $(0.26-5.33 \%$ in surficial samples, and up to $11.2 \%$ at depth in core 10 c, Figs. 3 and 4 ). The highest contributions were found in samples from the Thua Thien-Hué province (Fig. 3), due to the presence of factories and industrial-type activities. The incidence of furans in core $02 \mathrm{c}$ increases at $18-20 \mathrm{~cm}$ depth (from an average contribution of $2.0 \%$ to a maximum of $6.9 \%$, Fig. 3). According to the apparent SAR for this core $\left(0.60 \mathrm{~cm} \mathrm{y}^{-1}\right)$, this layer corresponds to the late $1960 \mathrm{~s}$-early 1970s, a period of intense military operations by the US Army. Also $\mathrm{PAH}$ congener distributions, measured in the same core approximately at the same depths, display a combustion originated composition (Giuliani et al., 2008) different from everywhere else. The

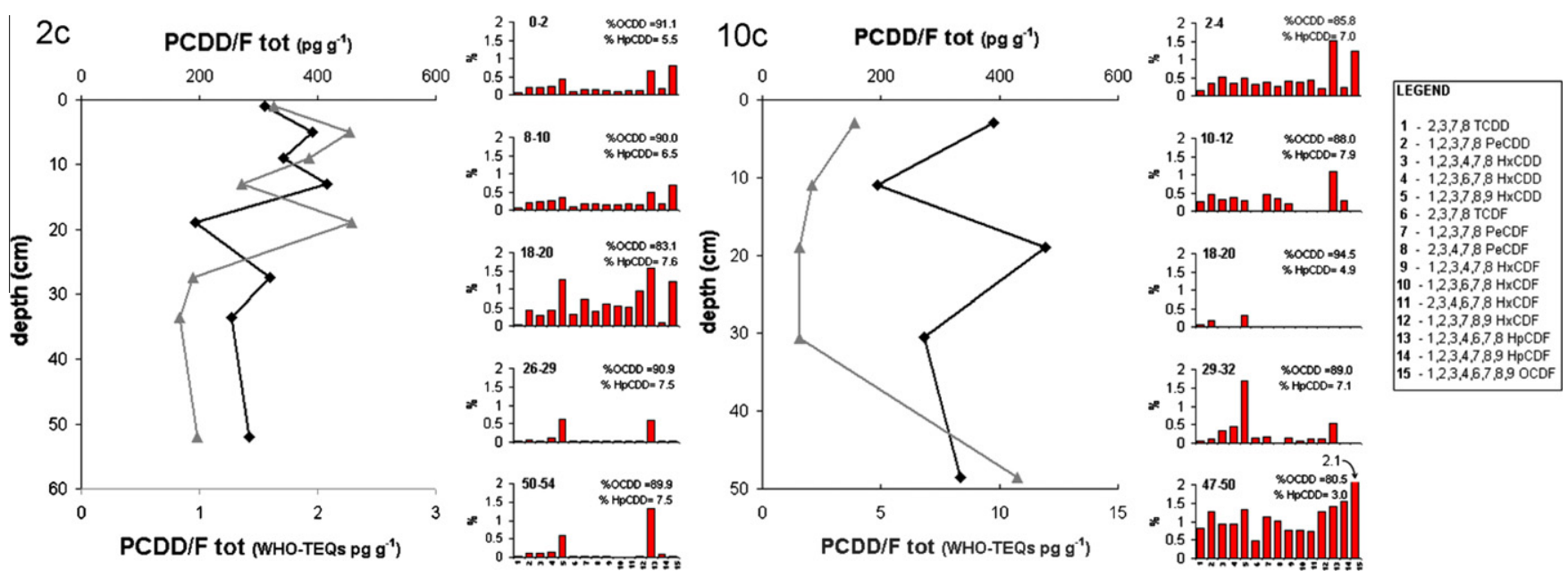

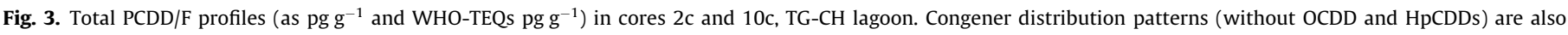
shown for selected depths, as \% contribution to the total. Values for OCDD and HpCDD are reported for each level. 


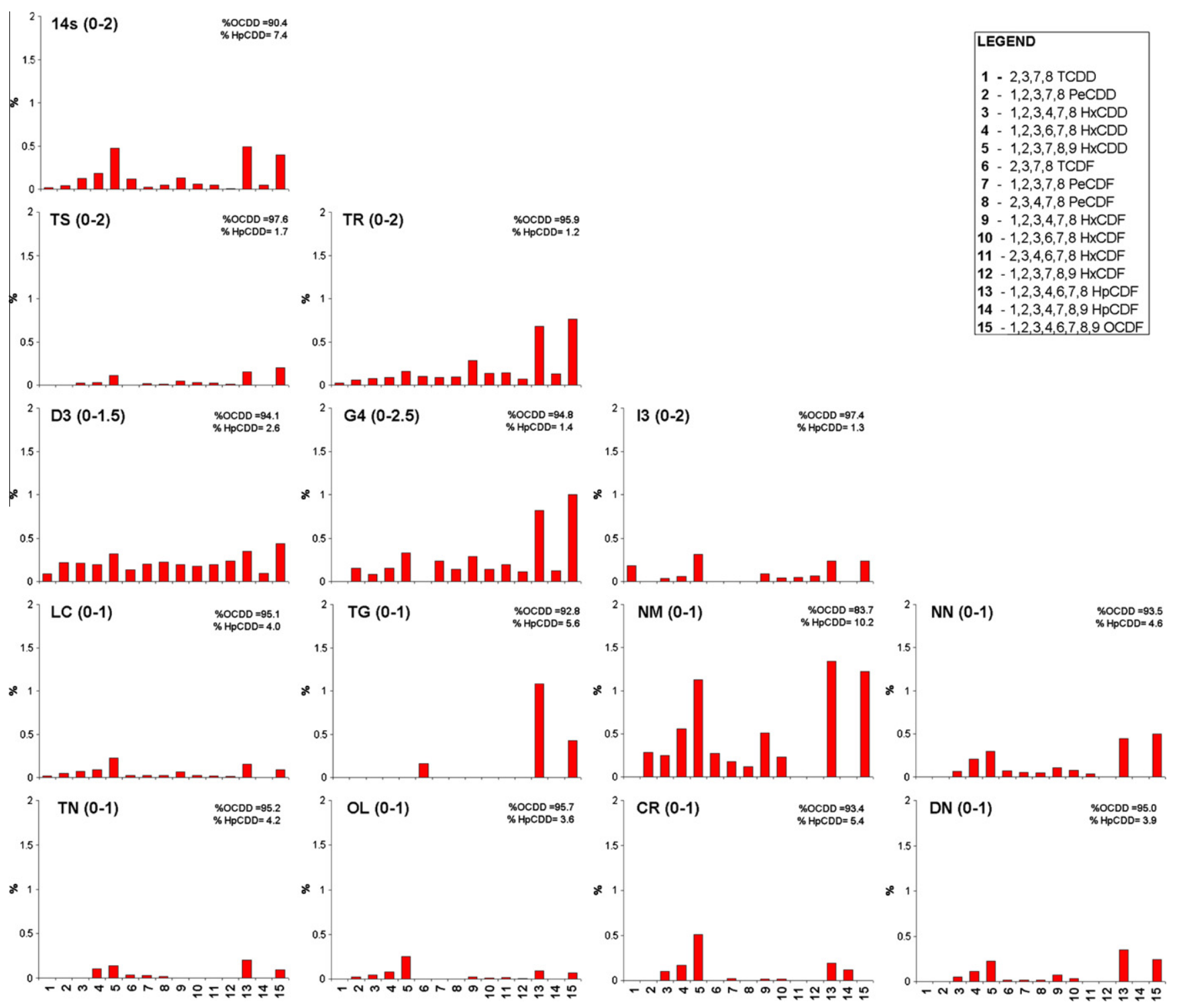

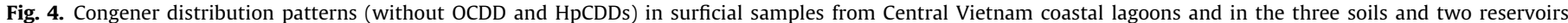
collected in the Thua Thien-Hué province. Values for OCDD and HpCDD are reported for each sample.

high relative importance of furans at depth in core $10 \mathrm{c}$ is likely linked to a local input. TCDD contents from 0.04 to $2.74 \mathrm{pg} \mathrm{g}^{-1}$, detected in lagoon samples from TG-CH and LC, the reservoir TR, and the soils D3 and I3 (and leading to \% contributions to total PCDD/Fs from 0.18 to 8.2, Figs. 3 and 4), are probably the only traces left in the system by the Agent Orange spraying.

The presence of naturally originated dioxins cannot be ruled out. Besides the production by forest fires, their formation in clays has been already observed in pre-industrial sediments (e.g., Rappe et al., 2001; Horii et al., 2008, and reference therein). This latter source seems to be characterised by a specific congener distribution: OCDD is dominant, with decreasing concentrations of other dioxins following reduction in the level of chlorination. Furthermore, concentrations of PCDFs are very low or non detectable, and 1,2,3,7,8,9-hexachlorodibenzo-p-dioxin predominates over the other 2,3,7,8-substituted HxCDD isomers (Rappe et al., 2001). As shown in Figs. 3 and 4, this pattern characterises the majority of our samples. It is thus plausible that an in situ formation may be able to partially explain the PCDD/F presence in these areas.
In order to highlight the similarities among the different PCDD/ F assemblages found in samples, both a Cluster Analyses (CA) and a Principal Component Analysis (PCA) were performed based on the concentration of each measured congener. The results are shown in Fig. 5a (CA on data from TG-CH), 5b and 5c (CA and PCA on all surficial samples, respectively). As expected, the variability is mostly a function of OCDD and HpCDD (component 1 and 2, respectively, in Fig. 5c). Both statistical analyses show that surficial samples from three minor lagoons (LC, OL and CR) and the two reservoirs (TR and TS) are much different from the other sites and among each other, thus confirming the predominant role of local, short-range sources. On the other hand, soil D3 and the surficial sediment sample $02 \mathrm{c}$ in the TG-CH lagoon seem very similar, as the soil could be the source for the lagoon sediment, probably through the $\mathrm{O}$ Lau river inflow into the lagoon. As far as TG-CH lagoon samples are concerned, Fig. 5a shows three main groups on the basis of different OCDD and, secondly, HpCDD abundances. Actually, the most distant samples are characterised by the highest (14s and $10 \mathrm{c}$ at $18-20 \mathrm{~cm}$ depth) and lowest (10c at $10-12 \mathrm{~cm}$ depth and $02 \mathrm{c}$ at $18-20 \mathrm{~cm}$ depth) OCDD contents. 
a
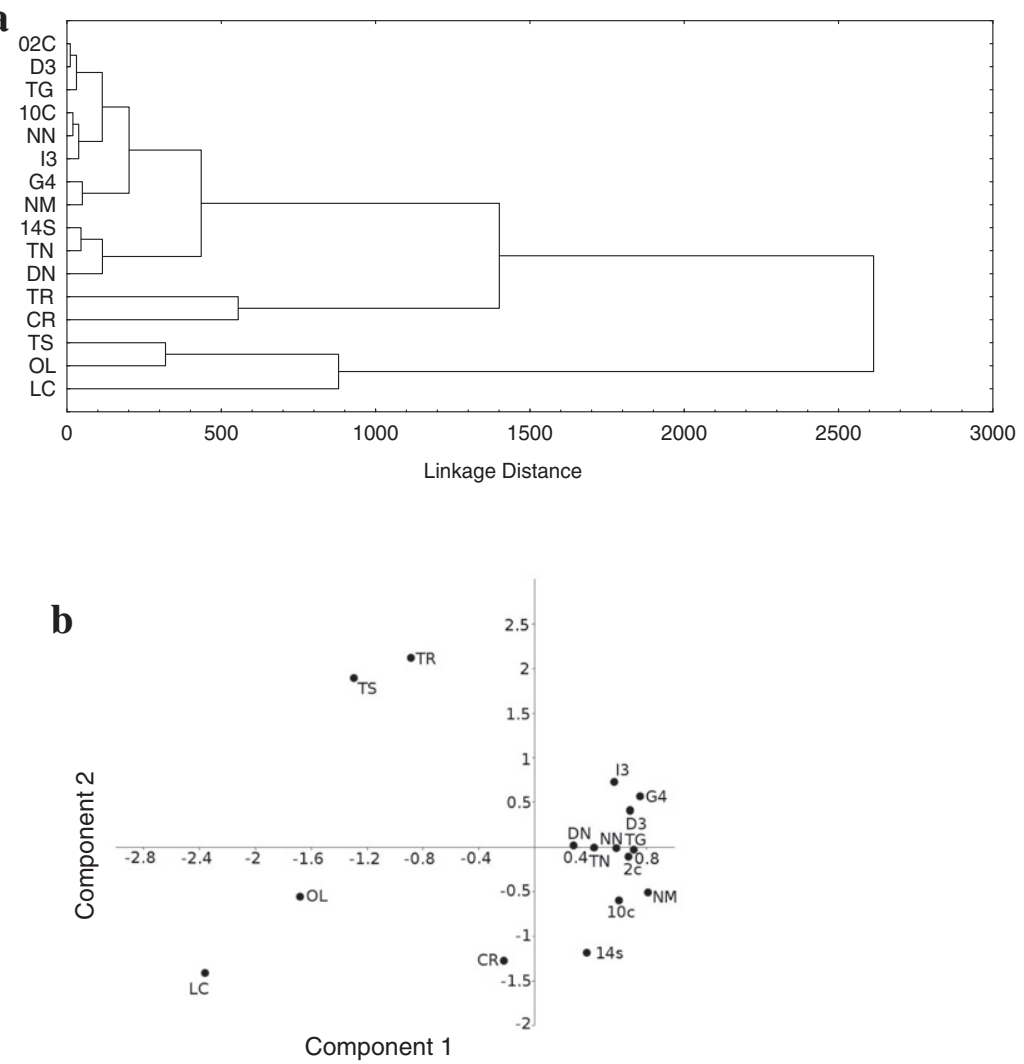

$02 c$

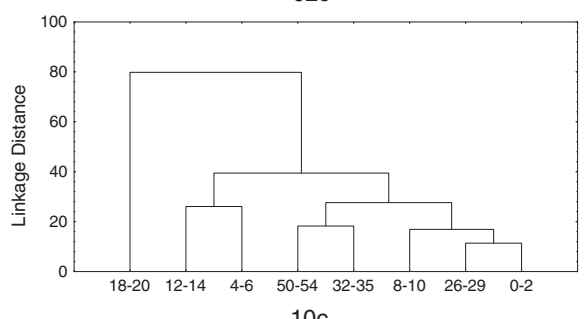

$10 c$

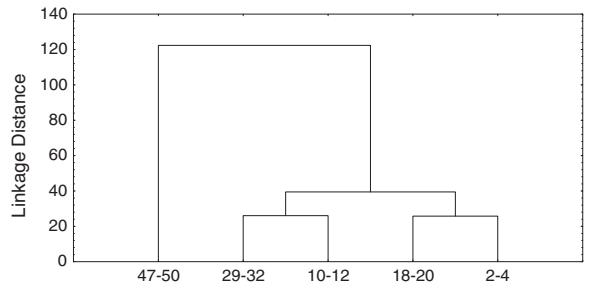

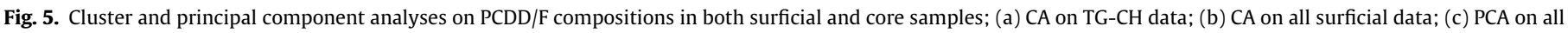
surficial data.

The results of the analyses carried out on sediment samples collected in Vietnamese coastal lagoons, soils and reservoirs did not highlight any particular problem related to the contamination by PCDD/Fs. Moreover, the congener profiles of dioxins and furans account for the predominance of OCDD, probably originated by combustion processes, whereas traces of TCDD, which was largely sprayed over the territory in the war period, could be found only in samples from the Thua Thien-Hue province (TG-CH lagoon, two soils and a reservoir) or nearby (the LC lagoon close to the city of Da Nang). In addition, natural PCDD/F formation processes cannot be excluded.

The absence or low presence of TCDD in the considered samples is consistent with the presence of effective Agent Orange's TCDD degradation processes (both on vegetation and in soils) soon after the spraying, as suggested by Young et al. (2004). In addition, it can be hypothesized that part of the sprayed TCDD migrated in ground waters, affecting nearby freshwater reservoirs. Removal processes linked to strong meteorological events could also be partially coresponsible for the low TCDD levels found in lagoon sediments. In conclusion, PCDD/F contamination appears to be still worrying only in the so-called "hot spots" that are now occupied by civilian populations, and affects TCDD levels in food.

\section{Acknowledgements}

Funds for this work were provided, in the framework of a bilateral project, by the Italian Ministry of Foreign Affairs (MAE), the Vietnamese Ministry of Science and Technology (MOST) and the Italian scientific institutions involved in the research. We are indebted with G. Capodaglio, for his help in sample collection. We would also thank the anonymous reviewer, whose suggestions improved our work. This is contribution No. 1693 from the Istituto di Scienze Marine, UOS of Bologna, Italy.

\section{References}

Bellucci, L.G., Frignani, M., Raccanelli, S., Carraro, C., 2000. Polychlorinated dibenzop-dioxins and dibenzofurans in surficial sediments of the Venice Lagoon (Italy). Marine Pollution Bulletin 40, 65-76.

$\mathrm{Cu}$, N.H., 1995. Generalization features of coastal lagoons in the centre of Vietnam. In: Thuc, P.V. (Ed.), Contributions of Marine Geology and Geophysics. Sci. Techn. Pub. House, Hanoi, pp. 113-120.

Dalla Valle, M., Marcomini, A., Sfriso, A., Sweetman, A.J., Jones, K.C., 2003. Estimation of $\mathrm{PCDD} / \mathrm{F}$ distribution and fluxes in the Venice Lagoon, Italy: combining measurement and modelling approaches. Chemosphere 51, 603-616.

Danis, B., Debacker, V., Trujilo Miranda, C., Dubois, P., 2006. Levels and effects of PCDD/Fs and co-PCBs in sediments, mussels and sea stars of the intertidal zone in the southern North Sea and the English Channel. Ecotoxicology and Environmental Safety 65, 188-200.

Dannenberg, D., Andersson, R., Rappe, C., 1997. Levels and patterns of polychlorinated dibenzo-p-dioxins, dibenzofurans and biphenyls in surface sediments from the Western Baltic Sea (Arkona Basin) and the Oder River estuarine system. Marine Pollution Bulletin 34, 1016-1024.

Dieu, L.V., 2006. Status and changes in the water quality of the Tam Giang-Cau Hai lagoon. Proceeding of the Vietnamese-Italian Seminar on the Coastal Lagoon Environments of Central Vietnam 85, 97.

Dwernychuk, L.W., Cau, D.H., Hatfield, C.T., Boivin, T.G., Hung, T.M., Dung, P.T., Thai, N.D., 2002. Dioxin reservoirs in southern Vietnam - A legacy of Agent Orange. Chemosphere 47, 117-137.

Eljarrat, E., De La Cal, A., Larrazabal, D., Fabrellas, B., Fernandez-Alba, A.R., Borrull, F. Marce, R.M., Barcelo, D., 2005. Occurrence of polybrominated diphenylethers, polychlorinated dibenzo-p-dioxins, dibenzofurans and biphenyls in coastal sediments from Spain. Environmental Pollution 136, 493-501.

EPA 2004. Exposure and human health reassessment of 2,3,7,8-tetrachlorodibenzop-dioxin (TCDD) and related compounds: National Academy of Sciences (NAS) review draft. <http://www.epa.gov/ncea/pdfs/dioxin/nas-review/>. 
Fattore, E., Benfenati, E., Mariani, G., Fanelli, R., 1997. Patterns and sources of polychlorinated dibenzo-p-dioxins and dibenzofurans in sediments from the Venice Lagoon, Italy. Environmental Science \& Technology 31, 1777-1784.

Frignani, M., Bellucci, L.G., Carraro, C., Favotto, M., 2001. Accumulation of polychloro dibenzo-p-dioxins and dibenzofurans in sediments of the Venice Lagoon and the industrial area of Porto Marghera. Marine Pollution Bulletin 42, 544-553.

Frignani, M., Piazza, R., Bellucci, L.G., Cu, N.H., Zangrando, R., Albertazzi, S., Moret, I. Romano, S., Gambaro, A., 2007. Polychlorinated biphenyls in sediments of the Tam Gan-Cau Hai Lagoon, Central Vietnam. Chemosphere 67, 1786-1793.

Gaus, C., Päpke, O., Dennison, N., Haynes, D., Shaw, G.R., Connell, D.W., Müller, J.F., 2001. Evidence for the presence of a widespread PCDD source in coastal sediments and soils from Queensland, Australia. Chemosphere 43, 549-558.

Gifford, J.S., Buckland, S.J., Judd, M.C., McFarlan, P.N., Anderson, S.M., 1996. Pentachlorophenol (PCP), PCDD, PCDF and pesticide concentrations in a freshwater lake catchment. Chemosphere 32, 2097-2113.

Giuliani, S., Sprovieri, M., Frignani, M., Cu, N.H., Mugnai, C., Bellucci, L.G., 2008. Presence and origin of polycyclic aromatic hydrocarbon in sediments of nine coastal lagoons in central Vietnam. Marine Pollution Bulletin 56, 1504-1512.

Goff, J.F., 1997. A chronology of natural and anthropogenic influences on coastal sedimentation, New Zealand. Marine Geology 138, 105-117.

Hagenmaier, H., Lindig, C., She, J., 1994. Correlation of environmental occurrence of polychlorinated dibenzo- $p$-dioxins and dibenzofurans with possible sources. Chemosphere 29, 2163-2174.

Horii, Y., Kannan, K., Petrick, G., Nachtigall, K., Yamashita, N., 2008. Novel evidence for natural formation of dioxins in ball clay. Chemosphere 70, 1280-1289.

Hu, J., Wan, Y., Shao, B., Jin, X., An, W., Jin, F., Yang, M., Wang, X., Sugisaki, M., 2005. Occurrence of trace organic contaminants in Bohai Bay and its adjacent Nanpaiwu River, North China. Marine Chemistry 95, 1-13.

Koistinen, J., Stenman, O., Haathi, H., Suonperä, M., Paasivirta, J., 1997. Polychlorinated diphenil ethers, dibenzo-p-dioxins, dibenzofurans and biphenils in seals and sediments from the Gulf of Finland. Chemosphere 35, 1249-1269.

Koh, C.H., Khim, J.S., Kannan, K., Villeneuve, D.L., Senthilkumar, K., Giesy, J.P., 2004. Polychlorinated dibenzo-p-dioxins (PCDDs), dibenzofurans (PCDFs), biphenyls (PCBs), and polycyclic aromatic hydrocarbons (PAHs) and 2, 3, 7, 8-TCDD equivalents (TEQs) in sediment from the Hyeongsan River, Korea. Environmental Pollution 132, 489-501.

Isosaari, P., Kohonen, T., Kiviranta, H., Tuomisto, J., Vartiainen, T., 2000. Assessment of levels, distribution and risks of polychlorinated dibenzopdioxins and dibenzofurans in the vicinity of a vinyl chloride monomer production plant. Environmental Science \& Technology 34, 2648-2689.

Isosaari, P., Pajunen, H., Vartiainen, T., 2002. PCDD/F and PCB history in dated sediments of a rural lake. Chemosphere 47, 575-583.

Mai, T.M., Doan, T.V., Huynh, T.M.H., Tarradellas, J., De Alancastro, F., Grandjean, D., 2007. Dioxin contamination in soils of Southern Vietnam. Chemosphere 67, 1802-1807.

Miyata, J.L., Huang, C.W., Tsai, H.T., Sheng, V.Z., Mase, Y., Aozasa, O., Ohta, S., 1995 Pollution by PCDDs and PCDFs in sediment from freshwater fish culture ponds near incineration sites for metal reclamation in Wan-Li, Taiwan, Republic of China. Chemosphere 31, 2779-2789.

Moon, H.-B., Choi, M., Choi, H.-G., Ok, G., Kannan, K., 2009. Historical trends of PCDDs, PCDFs, dioxin-like PCBs and nonylphenols in dated sediment cores from a semi-enclosed bay in Korea: tracking the sources. Chemosphere 75, 565571.

Müller, J., Haynes, D., McLachlan, M., Böhme, F., Will, S., Shaw, G.R., Mortimer, M., Sadler, R., Connell, D.W., 1999. PCDDs, PCDFs, PCBs and HCB in marine and estuarine sediments from Queensland, Australia. Chemosphere 39, 1707-1721.

Müller, J., Gaus, C., Prange, J.A., Päpke, O., Poon, K.F., Lam, M.H.W., Lam, P.K.S., 2002. Polychlorinated dibenzo-p-dioxins and polychlorinated dibenzofurans in sediments from Hong Kong. Marine Pollution Bulletin 45, 372-378.

Naito, W., Jin, J., Kang, Y., Yamamuro, M., Masunaga, S., Nakanishi, J., 2003. Dynamics of PCDDs/DFs and coplanar-PCBs in an aquatic food chain of Tokyo Bay. Chemosphere 53, 347-362.

NATO/CCMS 1988. Pilot study on international information exchange on dioxins and related compounds. Scientific basis for the development of the International Toxicity Equivalent Factor (I-TEF) method of risk assessment for complex mixtures of dioxins and related compounds. Report No. 176, Buxelles, pp. 56.

Okumura, Y., Yamashita, Y., Kohno, Y., Nagasaka, H., 2004. Historical trends of $\mathrm{PCDD} / \mathrm{Fs}$ and CO-PCBs in a sediment core collected in Sendai Bay, Japan. Water Research 38, 3511-3522.

Olie, K., Schecter, A., Constable, J., Kooke, R.M.M., Serne, P., Slot, P.C., de Vries, P., 1989. Chlorinated dioxins and dibenzofuran levels in food and wildlife samples in the north and south of Vietnam. Chemosphere 19, 493-496.
Pieper, A., Lorenz, W., Kolb, M., Bahadir, M., 1997. Determination of PCDD/F for hazard assessment in a municipal landfill contaminated with industrial sewage sludge. Chemosphere 34, 121-129.

Rappe, C., Andersson, R., Bonner, M., Cooper, K., Fiedler, H., Howell, F., Kulp, S.E., Lau, C., 1997. PCDDs and PCDFs in soil and river sediment samples from a rural area in the United States of America. Chemosphere 34, 1297-1314.

Rappe, C., Tysklind, M., Andersson, R., Brurns, P.C., Irvine, R.L., 2001. Dioxin in bal clay and kaolin. Organohalogen Compounds 51, 259-263.

Rose, C.L., McKay, W.A., 1996. PCDDs (dioxins) and PCDFs (furans) in selected UK lake and reservoir sites-concentrations and TEQs in sediment and fish samples. Science of the Total Environment 177, 43-56.

Ryoo, K.S., Ko, S., Hong, Y.P., Choi, J., Cho, S., Kim, Y., Bae, Y.J., 2005. Levels of PCDDs and PCDFs in Korean river sediments and their detection by biomarkers. Chemosphere 61, 323-331.

Sakurai, T., Kim, J., Suzuki, N., Matsuo, T., Li, D., Yao, Y., Masunaga, S., Nakanishi, J., 2000. Polychlorinated dibenzo-p-dioxins and dibenzofurans in sediment, soil, fish, shellfish and crab samples from Tokyo Bay area, Japan. Chemosphere 40 627-640.

Schecter, A., Dai, L.C., Päpke, O., Prange, J., Constable, J.D., Matsuda, M., Thao, D.V., Piskac, A., 2001. Recent dioxin contamination from Agent Orange in residents of a southern Vietnam city. Journal of Occupational Environmental Medicine 43, 435-443.

Schecter, A., Pavuk, M., Constable, J.D., Dai, L.C., Päpke, O., 2002. A follow-up: high level of dioxin contamination in Vietnamese from Agent Orange, three decades after the end of spraying. Journal of Occupational Environmental Medicine 44 218-220.

Schecter, A., Quynh, H.T., Pavuk, M., Päpke, O., Malisch, R., Constable, J.D., 2003. Food as a source of dioxin exposure in the residents of Bien Hoa City, Vietnam. Journal of Occupational Environmental Medicine 45, 781-788.

Schramm, K.W., Winkler, R., Casper, P., Kettrup, A., 1997. PCDD/F in recent and historical sediment layers of Lake Stechlin, Germany. Water Research 31, 1525 1531.

Scott-Clark, C., Levy, A. 2003. Spectre orange. The Guardian, Saturday 29, March.

Sericano, J.L., Brooks, J.M., Champ, M.C., Kennicutt, M.C., Makeyev, V., 2001. Trace contaminant concentrations in the Kara Sea and its adjacent rivers, Russia. Marine Pollution Bulletin 42, 1017-1030.

Startin, J., Rose, M., 2003. Dioxins and dioxinlike PCBs in food. In: Schecter, A. Gasiewicz, T.A. (Eds.), Dioxins and Health. Wiley, Hoboken, NJ, pp. 89-136.

Stellman, J.M., Stellman, S.D., Christian, R., Weber, T., Tomasello, C., 2003. The extent and patterns of usage of Agent Orange and other herbicides in Vietnam. Nature 422, 681-687.

Stringer, R.L., Costner, P., Johnston, P.A., 1995. PVC manufacture as a source of PCDD/Fs. Organohalogen Compounds 24, 119-123.

Suarez, M.P., Rifai, H.S., Palachek, R., Dean, K., Koenig, L., 2006. Distribution of polychlorinated dibenzo-p-dioxins and dibenzofurans in suspended sediments, dissolved phase and bottom sediment in the Houston Ship Channel. Chemosphere 62, 417-429.

Thom, P.V., 2006. Review on the environmental quality of some lagoons in Central Vietnam. Proceedings of the Vietnamese-Italian Seminar on the Coastal Lagoon Environments of Central Vietnam 38, 53.

Tyler, A.O., Millward, G.E., 1996. Distribution and partitioning of polychlorinated dibenzo-p-dioxins, polychlorinated dibenzofurans and polychlorinated biphenyls in the Humber estuary, UK. Marine Pollution Bulletin 32, 393-403.

Van den Berg, M., Birnbaum, L., Denison, M., De Vito, M., Farland, W., Feeley, M. Fiedler, H., Hakansson, H., Hanberg, A., Haws, L., Rose, M., Safe, S., Schrenk, D. Tohyama, C., Tritscher, A., Toumisto, J., Tysklind, M., Walker, N., Peterson, R.E. 2006. The 2005 World Health Organization reevaluation of human and mammalian toxic equivalency factors for dioxins and dioxin-like compounds. Toxicological Sciences 93, 223-241.

Vartiainen, T., Mannio, J., Korhonen, M., Kinnunen, K., Strandman, T., 1997. Levels of PCDD, PCDF and PCB in dated lake sediments in Subartic Finland. Chemosphere 34, 1341-1350.

Verschueren, K. 1983. Handbook of environmental data on organic chemicals. Van Nostrad Reinhold, 1073-1074.

Wade, T.L., Jackson, T.J., Gardinali, P.R., Chambers, L., 1997. PCDD/PCDF sediment concentration distribution: Casco Bay, Maine, USA. Chemosphere 34, 13591367.

Yamashita, N., Kannan, K., Imagawa, T., Villeneuve, D., Hashimoto, S., Miyazaki, A Giesy, J.P., 2000. Vertical profile of polychlotinated dibenzo-p-dioxins, dibenzofurans, naphthalenes, biphenyls, polycyclic aromatic hydrocarbons, and alkylphenols in a sediment core from Tokyo Bay, Japan. Environmenta Science \& Technology 34, 3560-3567.

Young, A.L., Giesy, J.P., Jones, P.D., Newton, M., 2004. Environmental fate and bioavailability of Agent Orange and its associated dioxin during the Vietnam War. Environmental Science and Pollution Research 11, 359-370. 